\title{
CLINICO-PATHOLOGICAL PROFILE AND SURGICAL OUTCOME IN VERTEBRAL COLLAPSE OF NEOPLASTIC ORIGIN
}

\author{
Kapil Jain ${ }^{1}$, Abhinav Jain'2, Jayesh Sardhara ${ }^{3}$, Amit Singh $^{4}$, Arun Kumar Srivastava ${ }^{5}$
}

${ }^{1}$ Consultant, Department of Neurosurgery, Max Super Speciality Hospital, Saket, New Delhi.

${ }^{2}$ Assistant Professor, Department of Radiodiagnosis, Hamdard Institute of Medical Sciences and Research \& HAHC Hospital, New Delhi.

${ }^{3}$ Senior Resident, Department of Neurosurgery, Sanjay Gandhi Postgraduate Institute of Medical Sciences, Lucknow.

${ }^{4}$ Senior Resident, Department of Neurosurgery, Sanjay Gandhi Postgraduate Institute of Medical Sciences, Lucknow.

${ }_{5}^{5}$ Associate Professor, Department of Neurosurgery, Sanjay Gandhi Postgraduate Institute of Medical Sciences, Lucknow.

ABSTRACT
BACKGROUND
Data addressing the clinical/histopathological profile and post-operative neurological outcome in patients of neoplastic
vertebral collapse is scarce. This study was done with an aim to learn about these facts in patients of vertebral collapse of
neoplastic origin from our region.

\section{METHODS}

It was an historical retrospective cum prospective study in which 56 patients operated for neoplastic vertebral collapse were included from historical case records. After pre-operative evaluation and recording of data, spinal cord decompression and tumour resection with/without instrumentation had been done depending on the individual case. All surgical details, intra-operative and post-operative events were also recorded. Biopsy of the surgical specimen was considered gold standard to define aetiology. Patients were given perioperative adjuvant therapies as per the recommended published protocols. Neurological status was reassessed after a minimum follow-up of 6 months. Descriptive statistics were applied on the data.

\section{RESULTS}

Most common primary tumour was plasmacytoma and most common primary site for spinal metastasis was thyroid. Thoracic spine was most commonly involved. Postero-lateral approach was used in 59\% of the primary tumours and 69\% of metastasis. Instrumentation was done in $31 \%$ and $33 \%$ patients of primary and secondary tumours respectively. There was no intra-operative mortality in the primary tumour group, but one post-operative mortality. In the metastasis group there were 2 intra-operative deaths, but no post-operative mortality. Improvement in Frankel grade was seen on follow-up in $68 \%$ primary tumours and $81 \%$ patients of metastasis. Subjective pain relief was present in $86 \%$ and $100 \%$ patients of primary and secondary tumours respectively.

\section{CONCLUSIONS}

The neurological outcome of neoplastic vertebral collapse was good with multimodality therapeutic approach approaching reestablishment of ambulation in $44-63 \%$ patients.

\section{KEYWORDS}

Neoplastic, Neurological Deficit, Pain Relief, Vertebral Collapse.

HOW TO CITE THIS ARTICLE: Jain K, Jain A, Sardhara J, et al. Clinico-pathological profile and surgical outcome in vertebral collapse of neoplastic origin. J. Evolution Med. Dent. Sci. 2016;5(71):5208-5213, DOI: 10.14260/jemds/2016/1180

\section{INTRODUCTION \\ Spine is unique among the other parts of skeletal system due to its load-bearing and nerve-protecting function. Loss of its structural integrity as a result of primary or metastatic tumours may cause severe pain and/or paralysis. These symptoms impair the ambulatory ability of the patients and worsen their quality of life, thus requiring surgical interventions. \\ Metastatic tumours are far more common than the primaries of spine.[1] In patients with metastatic disease, 30- $70 \%$ has involvement of spine. ${ }^{[2-4]}$}

Financial or Other, Competing Interest: None.

Submission 21-07-2016, Peer Review 20-08-2016,

Acceptance 26-08-2016, Published 03-09-2016.

Corresponding Author:

Dr. Abhinav Jain,

Assistant Professor,

Department of Radiodiagnosis,

Hamdard Institute of Medical Sciences and

Research \& HAHC Hospital, New Delhi-110062, India.

E-mail: drabhinavjain@gmail.com

DOI: $10.14260 /$ jemds/2016/1180
With an increase in survival of cancer patients with multimodality therapeutic approach, the need for management of symptomatic spinal metastasis has also increased.

To the best of our knowledge, there is no published Indian data in the indexed medical literature with reference to the clinical and histopathological profile including the neurological outcome after surgery in neoplastic vertebral collapse. In this communication, we present our experience with vertebral collapse of neoplastic aetiology and their outcome following neurosurgical treatment.

\section{METHODS}

In this historical retrospective cum prospective study, 56 patients of vertebral collapse of neoplastic aetiology presenting in the Department of Neurosurgery were included. Post-traumatic and post-infectious causes were excluded. These patients had been operated over an eightyear period (January 2000 - December 2008). Data of patients was collected from inpatient and pre-operative outpatient file records, discharge summaries and follow-up outpatient records. 
The presenting complaints, duration of symptoms, detailed clinical neurological assessment and radiological findings (level of involvement, number of vertebrae involved) were recorded for all study subjects. In patients with metastatic disease, site of primary tumour was searched as per the published recommended guidelines. Pre/postoperative investigations including chest X-ray, full skeletal survey, sonography (USG) abdomen, urine and serum electrophoresis for M-bands, prostate specific antigen, thyroid scanning, gynaecological examination including PAP smear, bone marrow biopsy, bone scan and local site biopsy were performed as and where indicated.

Collapsed vertebra (X-ray and MRI based) was defined as 1) Vertebra with fracture of end plates adjacent to the osteolytic lesion and 2) Vertebra with reduction of vertebral body height because of pathological fracture of the anterior and/or lateral cortex of vertebral body [Figure 1]. Vertebral height was considered to be reduced when the height of affected vertebral body was less than $90 \%$ of the estimated original height. This was calculated from an average of the corresponding measurements at adjacent unaffected levels above and below the involved vertebra. [5]

Pre-operative morbidity was scored objectively in form of Frankel grade. ${ }^{[6]}$

\section{Frankel Classification}

- Complete lesion (Paraplegia).

- Only sensory function present.

- Motor function present, but of no practical use (Non-ambulatory).

- Motor function present, sufficient to allow walking (Ambulatory).

- No neurologic signs or symptoms.

Patients underwent spinal cord decompression and tumour resection with/without instrumentation depending on the need of individual case, location, maximum bulk of the tumour, neuraxial compression and the decision of the operating surgeon. Surgical approach adopted along with mention regarding instrumentation (if done) was also noted down. Biopsy of the surgical specimen was considered gold standard for defining the aetiology of the collapse. Intra- and post-operative complications were recorded.

Patients were given post-operative adjuvant therapies as per the standard guidelines in the form of radiotherapy, chemotherapy and radioiodine ablation in the departments of radio-oncology, haematology and nuclear medicine respectively. Patients with minimum follow-up of 6 months were included in the follow-up analysis. Frankel score was assessed again at the time of last follow-up. Motor status was considered improved when the patient upgraded by one/more Frankel grade. Pain was considered improved when either it absolutely disappeared or decreased as per the patient's verbal statement. Objective pain scales were not used. Descriptive statistics were applied on the data.

\section{RESULTS}

Out of total 56 included cases of vertebral collapse, histopathology of the surgical specimen suggested 27 (48.2\%) primary tumours and 29 (51.8\%) secondary/metastases.
Most common primary tumour causing vertebral collapse was Plasmacytoma (12/27, i.e. $44.4 \%)$ followed by Ewing sarcoma $(4 / 27$, i.e. $14.8 \%)$. Other aetiologies seen in the primary tumour group were osteoclastoma (3), lymphoma (3), chordoma (1), aneurysmal bone cyst (1), haemangioma (1), round cell tumour (1) and giant cell tumour (1) [Table 1]. As per the historical records of metastatic vertebral collapse, primary site for the spinal metastasis could not be identified in $44.8 \%(12 / 29)$ cases. Most common primary site in spinal metastasis was thyroid (follicular carcinoma) in $34.5 \%$ $(10 / 29)$ cases. Other primary sites identified were liver (2), prostate (2), kidney (1), ovary (1) and cervix (1) [Table 1].

In the primary tumour group, the mean age at presentation was $45.4 \pm 16.6$ years. Male:female ratio was $4.4: 1$. Local pain was the most common presenting complaint in all $(100 \%)$ patients. Along with local pain, $25.9 \%(7 / 27)$ patients had radicular pain also. Limb weakness was also present in all (100\%) patients (Frankel grade A-D). Overall, $77.8 \%(21 / 27)$ patients were non-ambulatory (Frankel grade A-C). Sensory deficits were present in $74.1 \%(20 / 27)$ and bladder involvement was present in $48.1 \%(13 / 27)$ patients [Table 2].

In the metastasis group, the mean age at presentation was $52.2 \pm 11.5$ years. Male:female ratio was 1.2:1. Local pain was the most common presenting complaint in this group also. Approximately, $10 \%$ patients had radicular pain also in association with local pain. Limb weakness was present in all (100\%) patients. Overall, $86.2 \%$ (25/29) patients were nonambulatory. Sensory deficits were present in $93.1 \%(27 / 29)$ and bladder involvement was present in 48.3\% (14/29) patients [Table 2].

Thoracic spine was the most common site of collapse in $77.8 \%(21 / 27)$ cases of primary tumour. Similarly, in the metastatic group also, the thoracic spine was most common site of collapse in $82.7 \%(24 / 29)$ cases. None of the patients had C1/C2 or atlanto-axial joint involvement [Table 3].

As a special mention about 12 patients of plasmacytoma, all had solitary lesion and the pre-operative diagnosis was available, which was done on the basis of criteria laid by International Myeloma Working Group, 2003.[7,8] None of the patients had evidence of underlying systemic multiple myeloma. Although radiotherapy alone may be the treatment of choice in solitary plasmacytoma, surgery is required in a few patients with vertebral instability or in patients with radio-resistance.[7-10] All these 12 patients of solitary plasmacytoma were operated, because they all had accompanying vertebral collapse with spinal instability and progressive neurological deficits. Post-operative radiotherapy was given as per the standard protocols. [6,11-13] There is insufficient data for the role of adjuvant chemotherapy in solitary plasmacytoma.[6,11-13] and thus it was not given to these patients.

Surgical details, complications, mean follow-up period and outcome in terms of improvement/deterioration in motor status and pain were recorded [Table 4]. Posterolateral approach was more commonly used in our series, $59.3 \%(16 / 27)$ in the primary tumour group and $69.0 \%$ $(20 / 29)$ in the secondary tumour group. Overall, the instrumentation was done in $33.3 \%(9 / 27)$ of the primary tumour patients and $31.0 \%(9 / 29)$ of the secondary tumour patients. There was no intra-operative mortality in the primary group, but the post-operative mortality was $3.7 \%$ 
$(1 / 27)$. In the metastatic group, the intra-operative mortality was higher $(2 / 29=10.7 \%)$, because of uncontrollable bleeding (1 patient renal cell carcinoma and 1 follicular carcinoma of thyroid); there was no post-operative mortality.

In the primary tumour group, instrumentation was done in 9 patients (5 plasmacytoma, 2 Ewing's sarcoma, 1 aneurysmal bone cyst and 1 giant cell tumour). Among these 9 patients undergoing instrumentation, there was no intra- or post-operative mortality or post-operative complication. On follow-up (mean period $26.7 \pm 31.0$ months), $85.7 \%$ (6/7) had motor improvement and all $(100 \%)$ had pain improvement. One patient which did not show motor improvement was plasmacytoma of thoracic region operated from anterior approach. In the 18 non-instrumented patients of primary tumour group, $78.6 \%(11 / 14)$ patients improved in their Frankel grade and all (100\%) showed pain improvement as seen over a follow-up period of $28.7 \pm 25.2$ months.

Regarding metastases group, 8 patients had instrumentation and none of the instrumented patients suffered mortality or any post-operative complication. Seven patients could be followed for a period of $11.6 \pm 4.2$ months and $71.4 \%$ (5/7) showed motor improvement. Pain improvement was also present in $71.4 \%$ (5/7). Out of 21 noninstrumented patients, follow-up was available for 15 patients for a period of $21.3 \pm 20.0$ months. There was motor improvement in $66.7 \%(10 / 15)$ patients and pain relief in 93.3\% (14/15) patients.

Overall, patients of both primary and secondary groups had good neurological outcome in terms of motor improvement, which was $81.0 \%(17 / 21)$ in the primary group and $68.2 \%(15 / 22)$ in the secondary group. Pain relief was present in all $100 \%(21 / 21)$ patients from the primary group and $86.4 \%(19 / 22)$ of the patients with secondaries. Plasmacytoma patients, where half $(6 / 12)$ were operated by anterior approach and half $(6 / 12)$ by postero-lateral approach, 77.8\% (7/9) had motor improvement and all 100\% (9/9) had pain improvement. Among the follicular carcinoma of thyroid, $80.0 \%(8 / 10)$ were approached postero-laterally and $20.0 \%(2 / 10)$ anteriorly. Motor improvement was present in $75.0 \%(6 / 8)$ patients and all $100 \%(8 / 8)$ had pain relief.

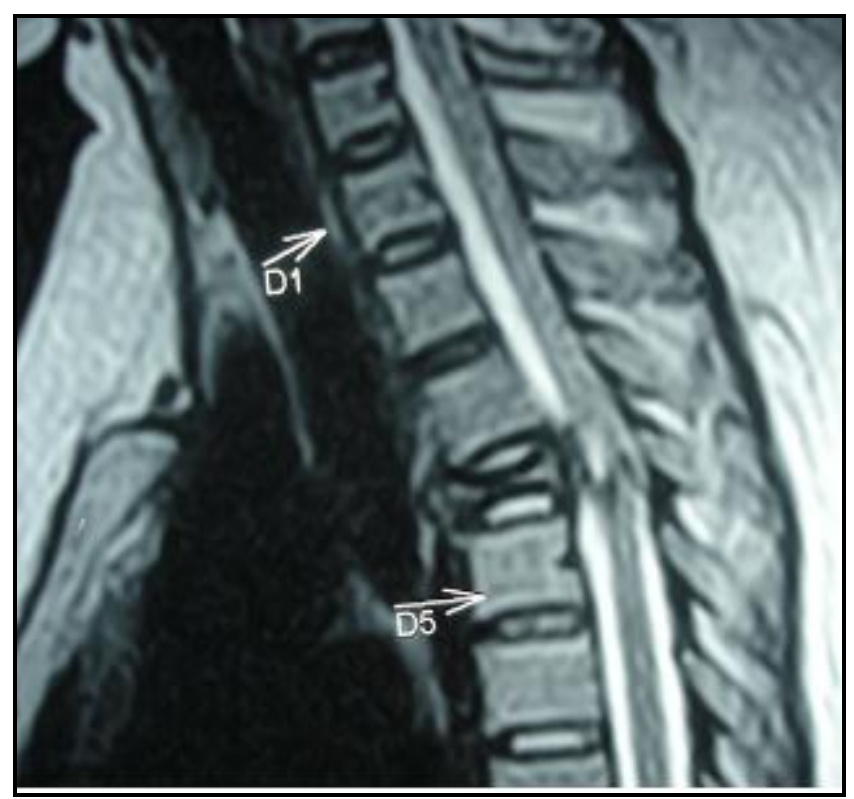

Fig. 1: T2 Weighted MRI Sagittal View showing Collapsed D4 Vertebra

\begin{tabular}{|c|c|}
\hline Histopathology of Primary Spinal Tumours - n (\%) & Primary Sites for Metastasis Spine - n (\%) \\
\hline Solitary Plasmacytoma - 12 (44.4) & Thyroid (Follicular Carcinoma) - 10 (34.5) \\
Ewing Sarcoma - $4(14.8)$ & Liver - $2(6.9)$ \\
Osteoclastoma - $3(11.1)$ & Prostate - $2(6.9)$ \\
Lymphoma - $3(11.1)$ & Kidney $-1(3.4)$ \\
Chordoma - $1(3.7)$ & Ovary - $1(3.4)$ \\
Aneurysmal bone cyst - $1(3.7)$ & Cervix - $1(3.4)$ \\
Haemangioma - $1(3.7)$ & Unknown - $12(41.4)$ \\
Round cell tumour - $1(3.7)$ & \\
Giant cell tumour - 1 (3.7) & \\
\hline \multicolumn{2}{|c|}{ Table 1: Histopathological Diagnosis in Neoplastic Vertebral Collapse } \\
\hline
\end{tabular}

\begin{tabular}{|c|c|c|c|}
\hline & & $\begin{array}{l}\text { Primary } \\
\text { Tumours }\end{array}$ & $\begin{array}{c}\text { Metastatic } \\
\text { Tumours }\end{array}$ \\
\hline \multicolumn{2}{|c|}{ Total number of cases } & 27 & 29 \\
\hline \multicolumn{2}{|c|}{ Mean age (in years) } & $\begin{array}{c}45.44 \pm 16.65 \\
(7-74)\end{array}$ & $\begin{array}{c}52.21 \pm 11.5 \\
(32-77)\end{array}$ \\
\hline \multicolumn{2}{|c|}{ Sex ratio (Male:Female) } & $4.4: 1$ & $1.2: 1$ \\
\hline \multirow{3}{*}{$\begin{array}{l}\text { Duration of } \\
\text { symptoms }\end{array}$} & $<1$ month & $5 / 27(18.5 \%)$ & $\begin{array}{c}6 / 29 \\
(20.7 \%)\end{array}$ \\
\hline & $\begin{array}{c}1-6 \\
\text { months }\end{array}$ & $12 / 27(44.4 \%)$ & $\begin{array}{c}16 / 29 \\
(55.2 \%)\end{array}$ \\
\hline & $>6$ months & $10 / 27(37.0 \%)$ & $\begin{array}{c}7 / 29 \\
(24.1 \%)\end{array}$ \\
\hline \multicolumn{2}{|c|}{$\begin{array}{l}\text { Motor weakness present } \\
\text { (Frankel Grade A-D) }\end{array}$} & $27 / 27(100 \%)$ & $\begin{array}{c}29 / 29 \\
(100 \%)\end{array}$ \\
\hline
\end{tabular}

\begin{tabular}{|c|c|c|c|}
\hline \multicolumn{2}{|c|}{$\begin{array}{l}\text { Non-ambulatory (Frankel } \\
\text { Grade A-C) }\end{array}$} & $21 / 27(77.8 \%)$ & $\begin{array}{c}25 / 29 \\
(86.2 \%)\end{array}$ \\
\hline \multirow{3}{*}{ Pain +} & $\begin{array}{l}\text { Local site } \\
\text { only }\end{array}$ & $20 / 27(74.1 \%)$ & $\begin{array}{c}26 / 29 \\
(89.7 \%)\end{array}$ \\
\hline & $\begin{array}{l}\text { Radicular } \\
\text { only }\end{array}$ & $0 / 27(0.0 \%)$ & $\begin{array}{l}0 / 29 \\
(0.0 \%)\end{array}$ \\
\hline & Both & $7 / 27$ (25.9\%) & $\begin{array}{c}3 / 29 \\
(10.3 \%) \\
\end{array}$ \\
\hline \multicolumn{2}{|c|}{ Sensory deficit +} & $20 / 27(74.1 \%)$ & $\begin{array}{c}27 / 29 \\
(93.1 \%)\end{array}$ \\
\hline \multicolumn{2}{|c|}{ Bladder involvement + } & $13 / 27(48.1 \%)$ & $\begin{array}{c}14 / 29 \\
(48.3 \%)\end{array}$ \\
\hline \multicolumn{4}{|c|}{$\begin{array}{c}\text { Table 2: Clinical Profile of Patients with Neoplastic } \\
\text { Vertebral Collapse }\end{array}$} \\
\hline
\end{tabular}




\begin{tabular}{|c|c|c|}
\hline $\begin{array}{c}\text { Level of } \\
\text { Involvement }\end{array}$ & $\begin{array}{c}\text { Primary } \\
\text { Tumour } \\
\text { Group } \\
\mathbf{N}(\%)\end{array}$ & $\begin{array}{c}\text { Metastatic } \\
\text { Tumour Group } \\
\mathbf{N}(\%)\end{array}$ \\
\hline Cervical & $2(7.4)$ & $1(3.4)$ \\
\hline Cervico-thoracic & $0(0.0)$ & $1(3.4)$ \\
\hline Thoracic & $20(74.1)$ & $24(82.7)$ \\
\hline Thoraco-lumbar & $1(3.7)$ & $0(0.0)$ \\
\hline Lumbar & $1(3.7)$ & $3(10.3)$ \\
\hline Lumbosacral & $2(7.4)$ & $0(0.0)$ \\
\hline Sacral & $3(11.1)$ & $0(0.0)$ \\
\hline Total & $\mathbf{2 7}$ & $\mathbf{2 9}$ \\
\hline Table 3: Vertebral Involvement in Tumours \\
of Spine (With Collapse)
\end{tabular}

\begin{tabular}{|c|c|c|c|}
\hline & & $\begin{array}{l}\text { Primary } \\
\text { Tumours }\end{array}$ & $\begin{array}{l}\text { Metastatic } \\
\text { Tumours }\end{array}$ \\
\hline \multirow{2}{*}{$\begin{array}{l}\text { Surgical } \\
\text { Approach }\end{array}$} & Anterior & $\begin{array}{c}10 / 27 \\
(37.0 \%)\end{array}$ & $9 / 29(31.0 \%)$ \\
\hline & Posterolateral & $\begin{array}{c}16 / 27 \\
(59.3 \%)\end{array}$ & $20 / 29(69.0 \%)$ \\
\hline \multicolumn{2}{|c|}{ Instrumentation + } & $\begin{array}{c}9 / 27 \\
(33.3 \%)\end{array}$ & $9 / 29(31.0 \%)$ \\
\hline \multicolumn{2}{|c|}{ Intra-operative mortality } & $0 / 27(0.0 \%)$ & $\begin{array}{c}3 / 29(10.3 \%) \\
\text { (Cause: } \\
\text { Bleeding) }\end{array}$ \\
\hline \multicolumn{2}{|c|}{ Post-operative mortality } & $\begin{array}{l}\text { 1/27 (3.7\%) } \\
\text { (Cause: } \\
\text { Pulmonary } \\
\text { embolism) }\end{array}$ & $0 / 26(0.0 \%)$ \\
\hline \multicolumn{2}{|c|}{ Other complications } & $\begin{array}{c}3 / 27 \\
(11.1 \%) \\
\text { (1 CSF leak, } \\
1 \text { wound } \\
\text { dehiscence } \\
\text { and } 1 \text { deep } \\
\text { vein } \\
\text { thrombosis) }\end{array}$ & $\begin{array}{l}3 / 29(10.3 \%) \\
\text { (1 CSF leak and } \\
2 \text { deep vein } \\
\text { thrombosis) }\end{array}$ \\
\hline \multicolumn{2}{|c|}{$\begin{array}{l}\text { Followed-up ( } \geq 6 \text { months) } \\
\text { patients }\end{array}$} & $\begin{array}{c}21 / 26 \\
(80.8 \%) \\
\end{array}$ & $22 / 26(84.6 \%)$ \\
\hline \multicolumn{2}{|c|}{$\begin{array}{l}\text { Duration of follow-up } \\
\text { (in months) }\end{array}$} & $\begin{array}{l}28.05 \pm 26.50 \\
\text { (Range 6- } \\
102 \text { ) }\end{array}$ & $\begin{array}{l}18.18 \pm 17.12 \\
\text { (Range } 7-72 \text { ) }\end{array}$ \\
\hline \multirow{3}{*}{$\begin{array}{l}\text { Motor } \\
\text { changes } \\
\text { on } \\
\text { follow-up }\end{array}$} & Status same & $\begin{array}{c}3 / 21 \\
(14.3 \%)\end{array}$ & $6 / 22(27.3 \%)$ \\
\hline & Improved & $\begin{array}{c}17 / 21 \\
(81.0 \%)\end{array}$ & $15 / 22(68.2 \%)$ \\
\hline & Deteriorated & $1 / 21(4.8 \%)$ & $1 / 22(4.5 \%)$ \\
\hline \multicolumn{2}{|c|}{$\begin{array}{l}\text { Ambulatory patients } \\
\text { (Pre-operative) }\end{array}$} & $\begin{array}{c}5 / 21 \\
(23.8 \%)\end{array}$ & $4 / 22$ (18.2) \\
\hline \multicolumn{2}{|c|}{$\begin{array}{l}\text { Ambulatory patients } \\
\text { (Post-treatment) }\end{array}$} & $\begin{array}{c}15 / 21 \\
(71.4 \%)\end{array}$ & $12 / 22(54.5)$ \\
\hline \multicolumn{2}{|c|}{$\begin{array}{l}\text { Subjective pain relief } \\
\text { (complete/partial) }\end{array}$} & $\begin{array}{c}21 / 21 \\
(100.0 \%)\end{array}$ & $19 / 22(86.4 \%)$ \\
\hline \multicolumn{4}{|c|}{$\begin{array}{c}\text { Table 4: Surgical and Follow-Up Details of Patients with } \\
\text { Neoplastic Vertebral Collapse }\end{array}$} \\
\hline
\end{tabular}

\section{DISCUSSION}

The terminology 'collapse' applies more appropriately to the spontaneous non-traumatic occurrences. Weakness of the vertebral body by tumours is one of the very important cause of collapse. This becomes even more important in today's world when the incidence of cancers is increasing and the people with tumours are living longer. Thus, we focused our study on such patients with vertebral collapse of neoplastic aetiology.
Vertebral column is the most common osseous site for secondaries. Conversely, primary spinal tumours are relatively rare comprising only $10 \%$ or less of all tumours to the spine.[2] In our series of operated neoplastic vertebral collapse, there was almost equal distribution of primary and secondary spinal tumours. This is contradictory to other reports mentioning secondaries being far more frequent. This discrepancy could have been because of the fact that we had selectively included patients with collapse, which required surgery whereas other reports consist of all spinal tumour patients either with or without collapse.

In the previously published reports - most common primary benign tumours were haemangioma, osteoblastoma and osteochondroma. Plasmacytoma and Ewing sarcoma were the most common primary malignant tumours of spine.[1,11,12,14-22]

Among the metastatic tumours of spine - lungs, breast, prostate and kidneys were the most important primary sites.[11,15,18,23] In the index study, Plasmacytoma was the most common primary tumour and thyroid was the most common primary site for spinal metastasis. This difference in aetiologies could be due to: (a) The pattern for the aetiology of vertebral tumours is different in our region with a different genetic and environmental background in contrast to the Western countries; (b) Certain aetiologies of primary vertebral tumours like plasmacytoma and secondary vertebral tumours like follicular carcinoma of the thyroid are more aggressive in causing vertebral damage and ultimately collapse; (c) It could be due to the referral bias also to our tertiary care hospital.

There was a male sex predilection for the primary spinal tumours (male:female ratio 4.4:1). This is in agreement with the previous reports.[12,24,25] In both primary and metastatic tumour groups, thoracic spine was most common site of involvement in $74 \%$ and $83 \%$ cases respectively. This fact also agree with the previously published data.[15,26] and can be explained by the fact that the thoracic spine is the longest segment of vertebral column and thus the mathematical probability of involvement is maximum there.

In the last 2 decades, more effective neurosurgical techniques have been developed to provide dorsal and ventral spinal stabilisation. This has allowed the surgeons to become more aggressive with spinal cord decompression and tumour resection. In general, the surgical approach is dictated by the segment of spine involved (Cervical, thoracic, lumbar, sacral), location of the tumour in spinal segment (Anterior, posterior, right, left or circumferential to the neural elements), nature of the tumour, type of spinal reconstruction or stabilisation required after tumour resection. Anterior approach helps to achieve better decompression in metastatic tumours. Vertebral body resection for the tumour is now most commonly performed via anterior approach followed by vertebral column reconstruction and anterolateral plating. Posterior stabilisation with instrumentation is indicated in those with significant damage to posterior elements, significant kyphosis, thoracolumbar junction lesions, 2 or more adjacent vertebrectomies.[22,27]

Recent literature has revealed that the surgical outcome has improved with advances in the surgical techniques for spinal metastasis. However, it is difficult to generalise because of the diversity of surgical approaches, 
decompressive and reconstructive techniques, patient variables and tumour pathology. Most series report that more than $50 \%$ patients of spinal metastasis receive significant neurological recovery and more than $90 \%$ patients receive pain relief.[28-30]

Even the more recent studies[13,31-34] support the fact that surgical treatment improves outcome in patients with spinal metastasis. Hirabayashi et al[31] reported that the ambulatory status improved from $38 \%$ in the pre-operative period to $71 \%$ in the post-operative period and there was neurological improvement in about $50 \%$ of the patients. Same findings were supported by other authors also, neurological improvement in up to $60 \%$ of the patients. ${ }^{[13,32-34]}$ Pain relief (Complete/partial) was seen in $56-96 \%$ of the patients.[13,31-34] Major complications including pneumothorax, sepsis, wound infection, wound dehiscence, pulmonary embolism and hardware failure, and minor complications including urinary infection, pulmonary infection and CSF leaks were reported in 11-32\% cases.[13,31-34]

To the best of our knowledge, there is no published Indian literature describing the neurological outcomes after surgery in neoplastic vertebral collapse. In the present study, we found neurological improvement (Upgradation of Frankel score by one/more) in $81 \%$ and $68 \%$ patients of vertebral collapse with primary or metastatic aetiology respectively. In the primary tumour group $24 \%$ patients were ambulatory in the pre-operative period, $71 \%$ were ambulatory in the postoperative period and $63 \%$ non-ambulatory patients achieved ambulation with the treatment. In the metastasis group 18\% patients were ambulatory in the pre-operative period, 55\% were ambulatory in the post-operative period and $44 \%$ nonambulatory patients became ambulatory after treatment. Pain relief (Complete/partial) was present in all of the primary tumour patients and $86 \%$ of the metastasis patients.

\section{REFERENCES}

1. Kelley SP, Ashford RU, Rao AS, et al. Primary bone tumours of the spine: a 42-year survey from the leeds regional bone tumour registry. Eur Spine J 2007;16(3):405-9.

2. Boland PJ, Lane JM, Sundaresan N. Metastatic disease of the spine. Clin Orthop Relat Res 1982;169:95-102.

3. Harrington KD. Metastatic disease of the spine. J Bone Joint Surg Am 1986;68(7):1110-5.

4. Wong DA, Fornasier VL, MacNab I. Spinal metastases: the obvious, the occult and the impostors. Spine 1990;15(1):1-4.

5. Taneichi H, Kaneda K, Takeda N, et al. Risk factors and probability of vertebral body collapse in metastases of the thoracic and lumbar spine. Spine 1997;22(3):239-45.

6. Chi JH, Bydon A, Hsieh P, et al. Epidemiology and demographics for primary vertebral tumors. Neurosurg Clin N Am 2008;19(1):1-4.

7. Hughes M, Soutar R, Lucraft $\mathrm{H}$, et al. Guidelines on the diagnosis and management of solitary plasmacytoma of bone, extramedullary plasmacytoma and multiple solitary plasmacytomas: update. British committee for standards in haematology, London (UK). 2009.

8. International Myeloma Working Group. Criteria for the classification of monoclonal gammopathies, multiple myeloma and related disorders: a report of the IMWG. Br J Haematol 2003;121(5):749-57.
9. Fenoy AJ, Greenlee JD, Menezes AH, et al. Primary bone tumors of the spine in children. J Neurosurg 2006;105(Suppl 4):252-60.

10. Voulgaris S, Partheni M, Gousias K, et al. Solitary plasmacytoma of the upper cervical spine: therapeutic considerations. J Neurosurg Sci 2008;52(2):55-9.

11. Jacobs WB, Perrin RG. Evaluation and treatment of spinal metastases: an overview. Neurosurg Focus 2001;11(6):e10.

12. Nemoto O, Moser RP, Van Dam BE, et al. Osteoblastoma of the spine. A review of 75 cases. Spine 1990;15(12):127280.

13. Holman PJ, Suki D, McCutcheon I, et al. Surgical management of metastatic disease of the lumbar spine: experience with 139 patients. J Neurosurg Spine 2005;2(5):550-63.

14. Cho DC, Sung JK. Palliative surgery for metastatic thoracic and lumbar tumors using posterolateral transpedicular approach with posterior instrumentation. Surg Neurol 2009;71(4):424-33.

15. Donthineni R. Diagnosis and staging of spine tumors. Orthop Clin North Am 2009;40(1):1-7.

16. Dimopoulos MA, Hamilos G. Solitay bone plasmacytoma and extramedullary plasmacytoma. Curr Treat Options Oncol 2002;3(3):255-9.

17. Garg S, Dormans JP. Tumors and tumor-like conditions of the spine in children. J Am Acad Orthop Surg 2005;13(6):372-81.

18. Healey JH, Brown HK. Complications of bone metastases: surgical management. Cancer 2000;88(Suppl 12):294051.

19. Hentschel SJ, Burton AW, Fourney DR, et al. Percutaneous vertebroplasty and kyphoplasty performed at a cancer center: refuting proposed contraindications. J Neurosurg Spine 2005;2(4):436-40.

20. Rao G, Ha CS, Chakrabarti I, et al. Multiple myeloma of the cervical spine: treatment strategies for pain and spinal instability. J Neurosurg Spine 2006;5(2):140-5.

21. Raskas DS, Graziano GP, Herzenberg JE, et al. Osteoid osteoma and osteoblastoma of the spine. J Spinal Disord 1992;5(2):204-11.

22. Weigel B, Maghsudi M, Neumann C, et al. Surgical management of symptomatic spinal metastases. Postoperative outcome and quality of life. Spine 1999;24(21):2240-6.

23. Loblaw DA, Laperriere NJ, Mackillop WJ. A populationbased study of malignant spinal cord compression in Ontario. Clin Oncol 2003;15(4):211-7.

24. Marsh BW, Bonfiglio M, Brady LP, et al. Benign osteoblastoma: range of manifestations. J Bone Joint Surg Am 1975;57(1):1-9.

25. York JE, Kaczaraj A, Abi-Said D, et al. Sacral chordoma: 40year experience at a major cancer center. Neurosurgery 1999;44(1):74-9.

26. Gasbarrini A, Cappuccio M, Mirabile L, et al. Spinal metastases: treatment evaluation algorithm. Eur Rev Med Pharmacol Sci 2004;8(6):265-74.

27. Sciubba DM, Witham TF, Gokaslan ZL. Management of metastatic spine disease with spinal cord compression. Neurosurg Quarterly 2007;17(1):40-7. 
28. Cooper PR, Errico TJ, Martin R, et al. A systematic approach to spinal reconstruction after anterior decompression for neoplastic disease of the thoracic and lumbar spine. Neurosurgery 1993;32(1):1-8.

29. Harrington KD. Orthopedic surgical management of skeletal complications of malignancy. Cancer 1997;80(Suppl 8):1614-27.

30. Sundaresan N, Digiacinto GV, Hughes JE, et al. Treatment of neoplastic spinal cord compression: results of a prospective study. Neurosurgery 1991;29(5):645-50.

31. Hirabayashi H, Ebara S, Kinoshita T, et al. Clinical outcome and survival after palliative surgery for spinal metastases: palliative surgery in spinal metastases. Cancer 2003;97(2):476-84.
32. Huang TJ, Hsu RW, Li YY, et al. Minimal access spinal surgery (MASS) in treating thoracic spine metastasis. Spine 2006;31(16):1860-3.

33. North RB, LaRocca VR, Schwartz J, et al. Surgical management of spinal metastases: analysis of prognostic factors during a 10-year experience. J Neurosurg Spine 2005;2(5):564-73.

34. Villavicencio AT, Oskouian RJ, Roberson C, et al. Thoracolumbar vertebral reconstruction after surgery for metastatic spinal tumors: long-term outcomes. Neurosurg Focus 2005;19(3):E8. 